\title{
A Cidade como experiênCia de APRENDIZAGEM: REFLEXÕES ILUSTRADAS SOBRE O CURRÍCUlo EdUCATIVO dA CidAde
}

The City as a Learning Experience: Illustrated Reflections on the Educational Curriculum of the City

\section{Joana Lúcio \\ CIEd - Centro de Investigação em Educação, Universidade do Minho, Portugal joana.lucio@ie.uminho.pt}

RESUMO: Para discutir o currículo educativo da cidade, é importante atender-se à definição de «Cidade Educadora» (Bernet, 1990), que determina ser possível aprender na cidade (ou seja, a cidade enquanto contexto/meio educativo), aprender da cidade (ou seja, a cidade enquanto agente educativo) e aprender a cidade (ou seja, a cidade enquanto conteúdo educativo). Estes dois últimos aspetos são particularmente relevantes, nomeadamente no que diz respeito à questão da intencionalidade que, no fundo, é aquilo que distingue uma «cidade educativa» (que são todas, na medida em que todas são passíveis de apreensão) de uma «Cidade Educadora». Neste artigo, discutiremos o currículo educativo da cidade na sua pluridimensionalidade, invocando os métodos visuais (fotografia e desenho) não apenas como ilustração de um argumento, mas também enquanto ferramentas de apreensão, apropriação e manipulação do contexto urbano e, nessa medida, da experiência educativa da cidade. Empiricamente, este artigo fundamenta-se num projeto de desenvolvimento local (2006-2011) baseado em Massarelos, no Porto (Portugal), e mais concretamente nos dados recolhidos junto de crianças e jovens com idades entre os 5-17 anos. Ao discutirmos as perceções, apropriações e projetos de crianças e jovens sobre a cidade, contribuímos para um currículo educativo da cidade mais integrador, mais participado e mais crítico.

Palavras-chave: cidade educadora, cidade educativa, desenvolvimento local, currículo escolar, Massarelos. 
RESUM: Per a discutir el currículum educatiu de la ciutat, és important tindre en compte la definició de «Ciutat Educadora» (Bernet, 1990), que determina que és possible aprendre a la ciutat (és a dir, la ciutat és context/medi educatiu), aprendre de la ciutat (és a dir, la ciutat és agent educatiu) i aprendre la ciutat (és a dir, la ciutat és contingut educatiu). Aquests dos últims aspectes són particularment rellevants, en particular pel que fa a la qüestió de la intencionalitat, que en el fons és el que distingeix a una «ciutat educativa» (que són totes, en la mesura en què totes són susceptibles d'aprehensió) d'una «Ciutat Educadora». En aquest article discutirem el currículum educatiu de la ciutat en la seua pluridimensionalitat, invocant els mètodes visuals (fotografia i disseny) no sols com a il·lustració d'un argument, sinó també com a eines d'aprehensió, apropiació i manipulació del context urbà i, en eixa mesura, de l'experiència educativa de la ciutat. Empíricament, aquest article es basa en un projecte de desenvolupament local (2006-2011) basat en Massarelos, Porte (Portugal), i més específicament en les dades recollides dels xiquets i joves de 5-17 anys. En discutir les percepcions, apropiacions i projectes de xiquets i joves sobre la ciutat, contribuïm a un currículum educatiu de la ciutat més integrador, més participatiu i més crític.

Paraules clau: ciutat educadora, ciutat educativa, desenvolupament local, currículum educatiu, Massarelos.

RESUMEN: Para discutir el currículo educativo de la ciudad, es importante tener en cuenta la definición de «Ciudad Educadora» (Bernet, 1990), que determina que es posible aprender en la ciudad (es decir, la ciudad es contexto/medio educativo), aprender de la ciudad (es decir, la ciudad es agente educativo) y aprender la ciudad (es decir, la ciudad es contenido educativo). Estos dos últimos aspectos son particularmente relevantes, en particular en lo que se refiere a la cuestión de la intencionalidad, que en el fondo es lo que distingue a una «ciudad educativa» (que son todas, en la medida en que todas son susceptibles de aprehensión) de una «Ciudad Educadora». En este artículo discutiremos el currículo educativo de la ciudad en su pluridimensionalidad, invocando los métodos visuales (fotografía y diseño) no sólo como ilustración de un argumento, sino también como herramientas de aprehensión, apropiación y manipulación del contexto urbano y, en esa medida, de la experiencia educativa de la ciudad. Empíricamente, este artículo se basa en un proyecto de 
desarrollo local (2006-2011) ubicado en Massarelos, Porto (Portugal), y más específicamente en los datos recogidos de los niños y jóvenes de 5-17 años. Al discutir las percepciones, apropiaciones y proyectos de niños y jóvenes sobre la ciudad, contribuimos a un currículo educativo de la ciudad más integrador, más participativo y más crítico.

Palabras clave: ciudad educadora, ciudad educativa, desarrollo local, currículo educativo, Massarelos.

ABSTRACT: To discuss the educational curriculum of the city it is important to bear in mind the definition of the "Educating City" (Bernet, 1990), which determines that it is possible to learn in the city (that is, the city is an educational context/environment), learn from the city (that is, the city is an educational agent) and learn the city (that is, the city is educational content). These two latter aspects are especially relevant, particularly in reference to the question of intentionality, which in the end is what distinguishes an "educational city" (which all cities are, in that they can all be apprehended or understood) from an "Educating City". In this article we discuss the educational curriculum of the city in its pluridimensionality, invoking visual methods (photography and design) not only to illustrate an argument, but also as tools of apprehension, appropriation and manipulation of the urban context and, in that sense, of the educational experience of the city. This article draws on the empirical experience of a local development project (2006-2011) based in Massarelos, Porto (Portugal), and specifically on the data gathered from children and young people aged between 5 and 17 years old. By discussing the children's and young people's perceptions, appropriations and projects regarding the city, we contribute to a more integrating, more participative and more critical educational curriculum of the city.

KEYWORDS: educating city, educational city, local development, educational curriculum, Massarelos. 


\section{Introdução}

$\mathrm{P}$ ela sua complexidade, dimensão, diversidade (interna e externa) e significados, é possível analisar a cidade sob diversos pontos de vista, que são afinal referenciais de construção de conhecimento sobre o espaço urbano e as lógicas de apreensão e apropriação de indivíduos e organizações em relação ao local que habitam: podemos analisar a cidade do ponto de vista da sua História, da sua Geografia, da sua Arquitetura, do ponto de vista de quem a habita vs. de quem a olha de passagem, do ponto de vista da cultura, do acesso, da dicotomia público-privado, etc.

J. Borja e Z. Muxí (2003) fazem uma síntese daquilo que é a vida contemporânea das cidades no mundo ocidental, referindo que «la evolución de muchas de las grandes ciudades europeas y americanas parece condenar a reliquias del pasado la imagen de la ciudad como espacio público, como lugar o sistema de lugares significativos, como heterogeneidad y como encuentro» (Borja \& Muxí, 2003: 25). O que podemos depreender é que as cidades atuais, sendo cada vez maiores e mais densamente povoadas, são também, cada vez mais, contextos de isolamento e exclusão, em que os indivíduos partilham cada vez menos vivências, e estas se tornam, necessariamente, cada vez menos significativas. São contextos onde os indivíduos têm cada vez mais dificuldade em antever sentidos e, consequentemente, atribuir significados; onde as identidades tendem a fragmentar-se pela ausência de um «porto seguro» identitário. O que encontramos nos ensaios de autores como L. Benevolo (2006) - arquiteto e historiador -, K. Lynch (2007, 2009) - urbanista - e F. Ascher (2010) - sociólogo e politólogo - sobre as cidades numa perspetiva socio-histórica vai também, de certa forma, nesse sentido. Ascher (2010), especificamente, mobiliza a metáfora da «rede» para caracterizar o tecido social que, atualmente, encontramos nas cidades: a multiplicação das relações sociais, aliada à diversificação da sua natureza e à multiplicidade dos modos de comunicação, conduz a que «as estruturas sociais que emergem hoje, baseadas em laços fracos e muito numerosos e entre organizações e indivíduos muitas vezes afastados uns dos outros, [sejam] de tipo reticular» (Ascher, 2010: 46).

Propomos uma discussão sobre a cidade enquanto experiência de aprendizagem a partir de um «cenário» crítico e problematizante: poderão as cidades 
atuais ser contextos de desenvolvimento social e educativo para indivíduos e grupos? O que de educativo e educador é ainda possível reconhecer no contexto urbano? O que, na cidade, é ainda dialética, espaço de memória(s) e projeto(s) e arquétipo daquilo que se pode designar como «bem comum»? O que ensina a cidade - formal, informal e não formalmente - àqueles que a habitam? Que papel têm e/ou podem ter as crianças e os jovens na construção da cidade e, em última análise, enquanto cidadãos? Que plataformas podem potenciar a sua conexão ao tecido urbano (e, logo, ao local)?

\section{Cidade e sentido(s) educativo(s): um enquadramento}

Educação é relação; o processo educativo é, eminentemente, um processo relacional, de comunicação, partilha e troca. Antes de existir a escola, já existia a educação; se/quando a escola deixar de ser a instituição educativa por excelência, continuará a existir a educação. Inclusive, a educação de um indivíduo não está limitada pelos tempos, espaços e agendas escolares; aprende-se ao longo e ao largo da vida. Conforme explicita J. Pamiès (2007), «la educación comprende muchos más parámetros y agentes de los que habitualmente suelen reconocerse (familia, escuela) y que implican a toda la sociedad», acrescentando que «la dimensión educadora de la ciudad es muy anterior al establecimiento - importantísimo a todos los nivelesdel sistema educativo reglado» (Pamiès, 2007: 338). As cidades são, assim, espaços privilegiados para o desenvolvimento integral dos indivíduos e dos grupos, por nelas encontrarem mais, melhores e mais diversificadas oportunidades de acesso ao conhecimento, aquisição e desenvolvimento de competências, debate, interações significativas e, consequentemente, estímulo à construção identitária. Se a educação é uma dimensão fundamental da experiência humana, a cidade é um contexto especialmente favorável à construção de sentido(s) para essa experiência.

Segundo K. Lynch (2007), «os locais têm um sentido maior ou menor, tal como os acontecimentos. As atividades e as celebrações associadas a um local apoiam a sua perceção, desde que sejam elas próprias percecionadas como vívidas e coerentes» (Lynch, 2007: 127). Isto significa que, quanto mais frequentes ou temporalmente prolongadas forem as experiências de determinado 
tipo, em determinado espaço, mais sólidos são os significados que lhes são atribuídos, quer ao espaço, quer às experiências. Estes significados, sendo especificados ao nível do indivíduo (por relação à sua história, às suas experiências), são socialmente construídos e, por isso, partilhados e difundidos. Por referência às experiências positivas, Lynch (2007) considera que «um local bom é aquele que, de algum modo adequado à pessoa e à sua cultura, consegue tornar essa pessoa consciente da sua comunidade, do seu passado, [...] [e do] tempo e do espaço em que estes se integram» (Lynch, 2007: 137).

\section{O currículo educativo da cidade: reflexões «ilustradas»}

Sendo um aspeto determinante da vida dos indivíduos, a atribuição e o reconhecimento de sentidos (em relação a objetos, locais, indivíduos, fenómenos) é um processo fundamental do acesso à informação e do seu processamento e, consequentemente, de uma interação mais eficaz e mais satisfatória. No entanto, e conforme alerta Lynch (2007), a tendência, ao nível da gestão dos espaços e tempos urbanos, é muito mais amiúde no sentido da supressão da «legibilidade dos locais» (Lynch, 2007: 141), do que no sentido inverso. Verifica-se, segundo o autor, uma proliferação de espaços de natureza ambígua, cujas formas de usufruto não são evidentes e cuja apropriação é, consequentemente, difícil. Nesse sentido, propomos uma discussão sobre a importância dos sentidos - aquele(s) que é(são) idealizado(s) por quem desenha ou organiza o espaço e aquele(s) que é(são) construído(s) por quem dele usufrui - na apropriação dos espaços e, em concreto, da cidade.

Toda a prática educativa pressupõe um currículo. Na escola, o currículo refere-se às experiências de aprendizagem implementadas pela instituição e que deverão ser vivenciadas pelos estudantes, incluindo os conteúdos que deverão ser abordados no processo de ensino-aprendizagem e a metodologia utilizada para os diferentes níveis de ensino. Quando se fala em Cidade Educadora, o conceito de currículo assume uma definição mais fluida, mas ainda assim visível: falamos da cidade enquanto conteúdo, contexto e agente educativo (Bernet, 1990). 
Segundo Marina, Rodríguez e Vintró (2007), «educa toda a pessoa ou instituição que influencia as crenças, os sentimentos, os comportamentos e os conhecimentos e, portanto, ajuda a desenvolver as potencialidades das pessoas» (Marina, Rodríguez \& Vintró, 2007, p. 80).

Se é relativamente simples pensar na cidade enquanto contexto educativo (ou seja, enquanto local onde acontece aprendizagem) ou até mesmo enquanto conteúdo educativo (ou seja, enquanto objeto passível de apreensão), será eventualmente menos imediata a compreensão da cidade enquanto agente educativo pleno de intencionalidades. É esse o desafio que nos é colocado pelo conceito de «Cidade Educadora» (Bernet, 1990; Gómez-Granell \& Vila, 2003; Merino \& Plana, 2007; Villar, 2007): pensar sobre as interpelações que a cidade nos faz, sobre as permissões e as impossibilidades que nos apresenta, sobre os diferentes discursos e agendas que nela coexistem.

Para sustentar este argumento, proponho uma «deriva fotográfica» pela cidade do Porto (Portugal) e pelo currículo explícito (ou formal), implícito (ou informal) e reclamado ou transgressor (não formal ou contra-formal) que a compõem.

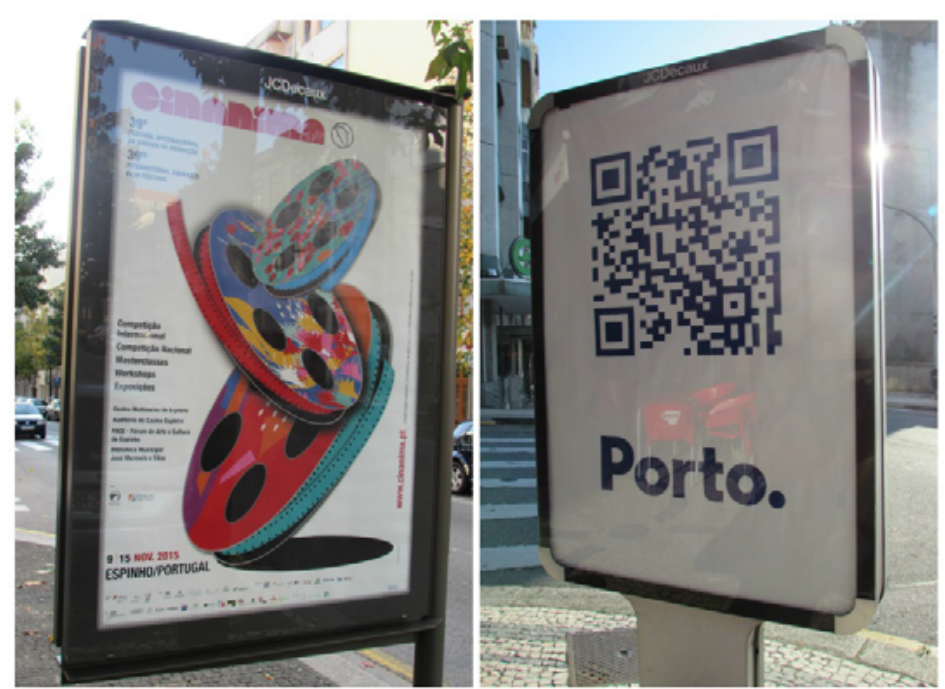

Figura 1. Currículo explícito da cidade | C Joana Lúcio (2015). 
Nesta primeira imagem (figura 1), temos evidência do que podemos designar como o «currículo explícito da cidade»: a agenda cultural, a identidade oficial da Câmara Municipal do Porto, o uso de espaços/plataformas «próprios para o efeito».

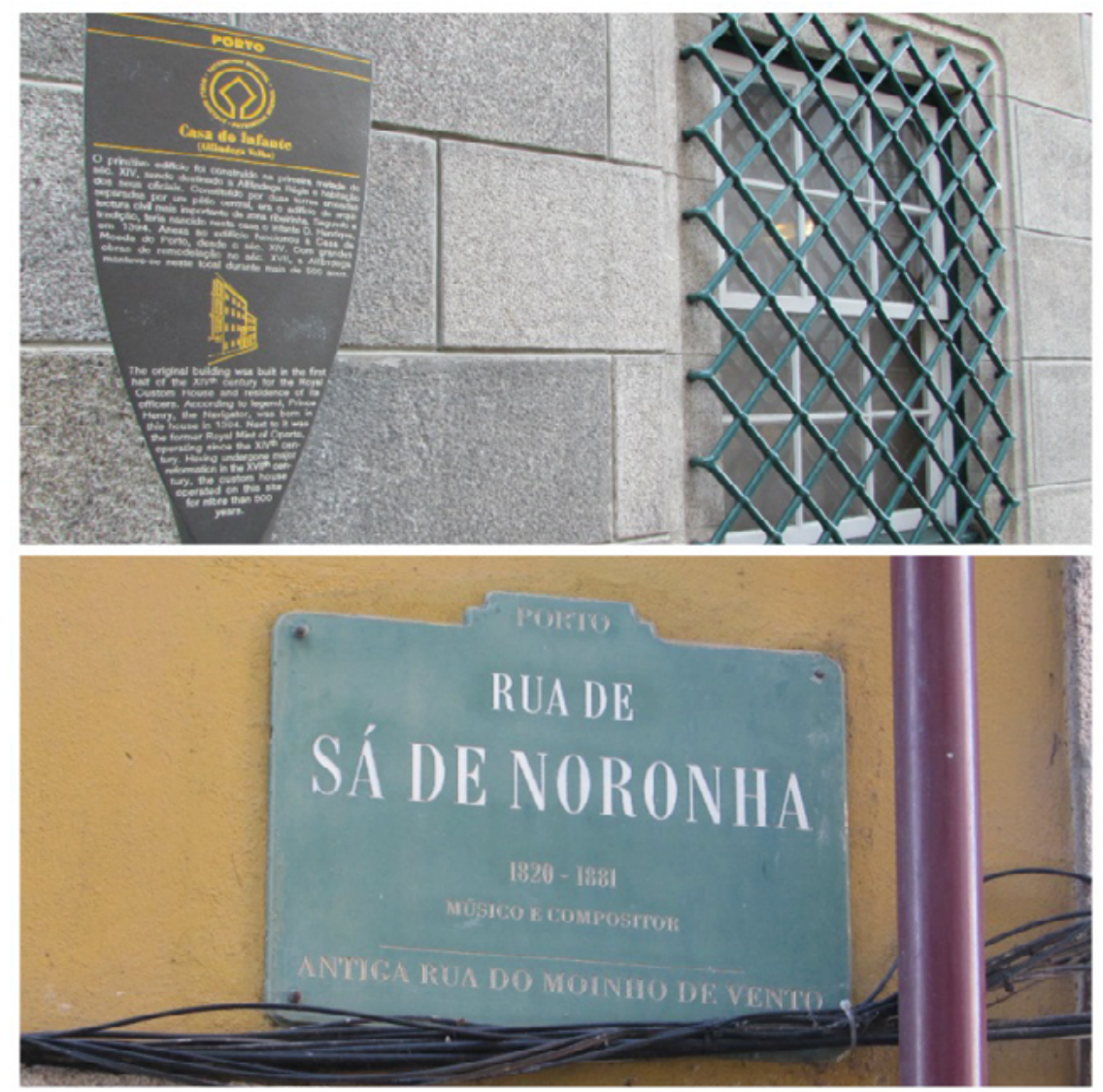

Figura 2. Currículo explícito da cidade | @ Joana Lúcio (2015).

$\mathrm{Na}$ imagem seguinte (figura 2), continuamos a estar perante a dimensão mais explícita e mais formal do currículo educativo da cidade: desta feita, o que está em causa é a História, o «quem somos, de onde vimos». 

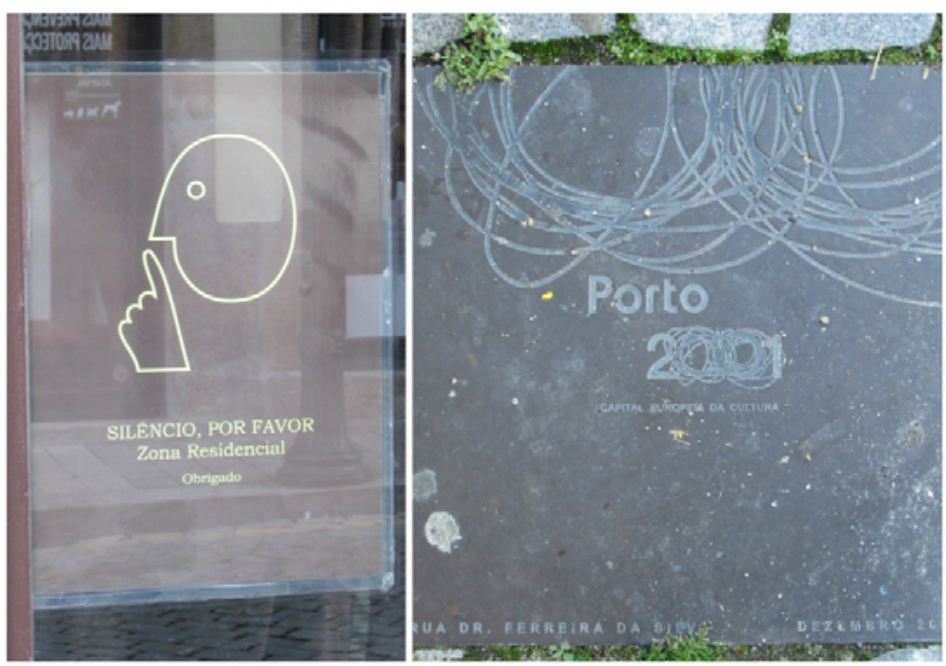

Figura 3. Currículo explícito da cidade | @ Joana Lúcio (2015).

A mensagem contida nesta imagem (figura 3) continua a ser bastante formal, mas já se encontra num formato mais alternativo. À esquerda, um sinal habitual à porta dos estabelecimentos de diversão noturna localizados na zona histórica da cidade, e à direita uma placa implantada num dos passeios da cidade, alusiva ao Porto, Capital Europeia da Cultura 2001. Em qualquer destes casos, bem como nos anteriores, tanto a mensagem como as identidades do seu emissor e do seu recetor são explícitas.
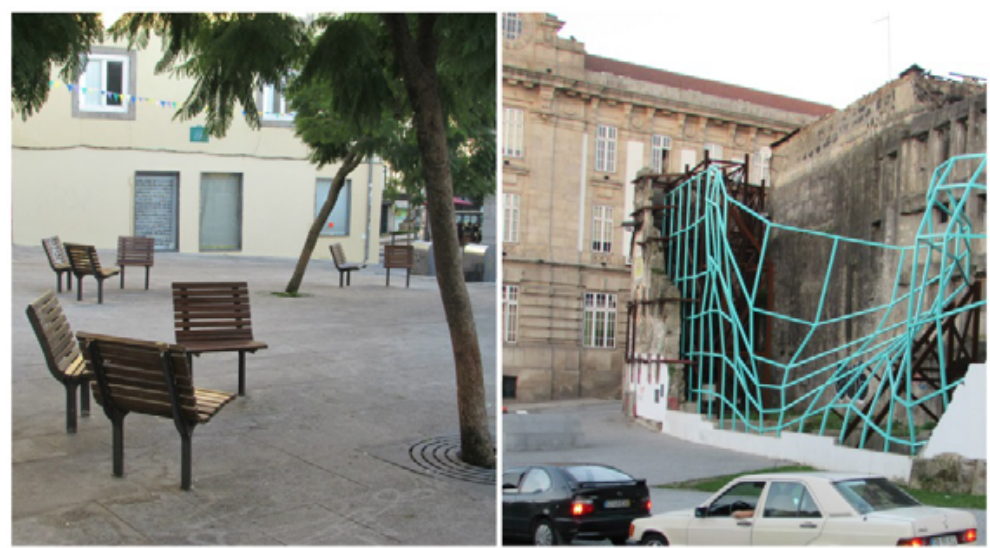

Figura 4. Currículo explícito da cidade | C Joana Lúcio (2015). 
Nas duas situações seguintes (figura 4), estando ainda no domínio do formal - visto que os interlocutores estão claramente identificados - estamos perante mensagens de um tipo mais subtil. À esquerda, o mobiliário urbano e a informação que a sua disposição nos dá sobre as possibilidades de usufruto e apropriação dos espaços da cidade. À direita, a ruína e a decadência física da cidade transformadas em instalação artística (com o apoio da Câmara Municipal do Porto).

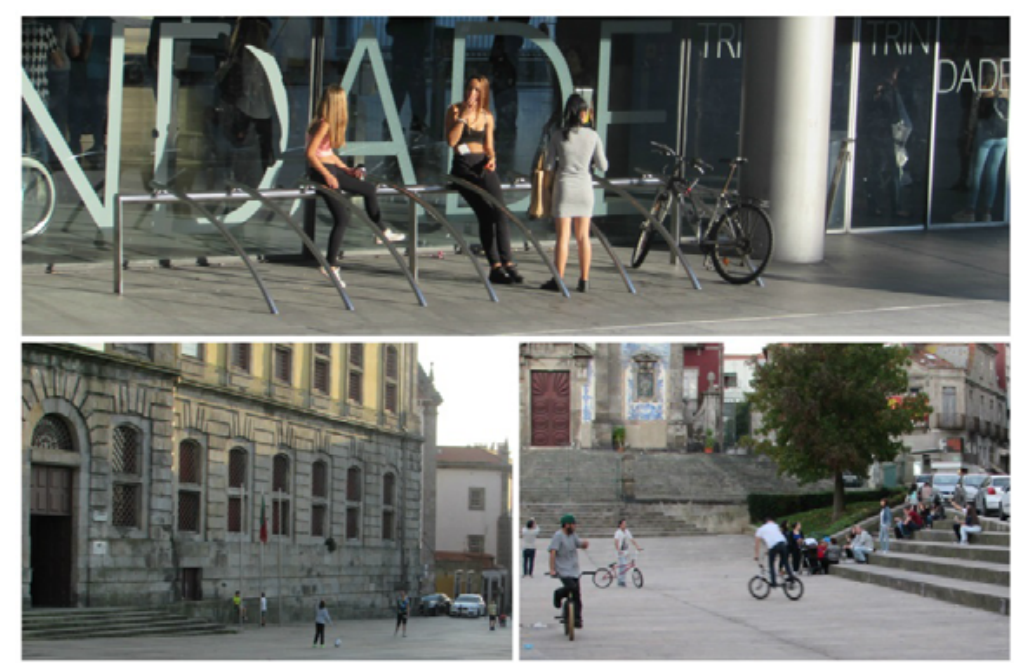

Figura 5. Currículo implícito e reclamado da cidade | (C) Joana Lúcio (2015).

Nestas três imagens (figura 5), temos algumas evidências do currículo implícito ou informal da cidade, mas também daquilo que designámos anteriormente como o currículo «reclamado» ou «transgressor». Em baixo, à esquerda, crianças jogam à bola no grande espaço (público) aberto em frente à antiga Cadeia da Relação do Porto, que é frequentemente utilizado como estacionamento (à noite), como mercado (ao fim de semana) ou como palco para eventos (dias de concertos, S. João, etc.). À direita, vemos jovens a fazer acrobacias com bicicletas e pessoas sentadas, no adro da Igreja da Batalha. Em cima, jovens reclamam a estrutura para aparcamento de bicicletas junto à estação de metro da Trindade como espaço de permanência. Em nenhum dos casos havia sinalização que proibisse estas atividades (o que muitas vezes acontece). 

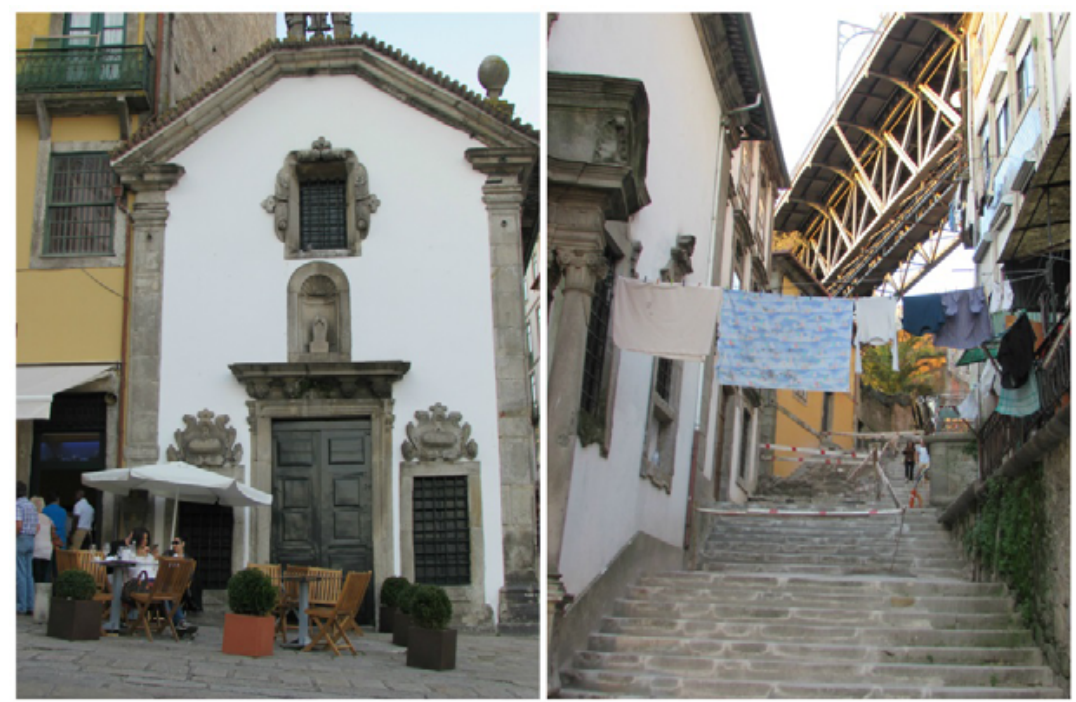

Figura 6. Currículo reclamado da cidade | C Joana Lúcio (2015).

Não apenas os jovens reclamam ou transgridem o currículo da cidade: nesta imagem (figura 6), à esquerda, uma esplanada de um café ou restaurante prolonga-se pela fachada de uma igreja do centro histórico; à direita, e na mesma zona, um estendal que atravessa uma via de circulação pedonal, desde a fachada de uma casa até à lateral de uma igreja. Em ambos os casos, a apropriação «transgressora» do espaço urbano é evidente, embora feita de forma ordenada.

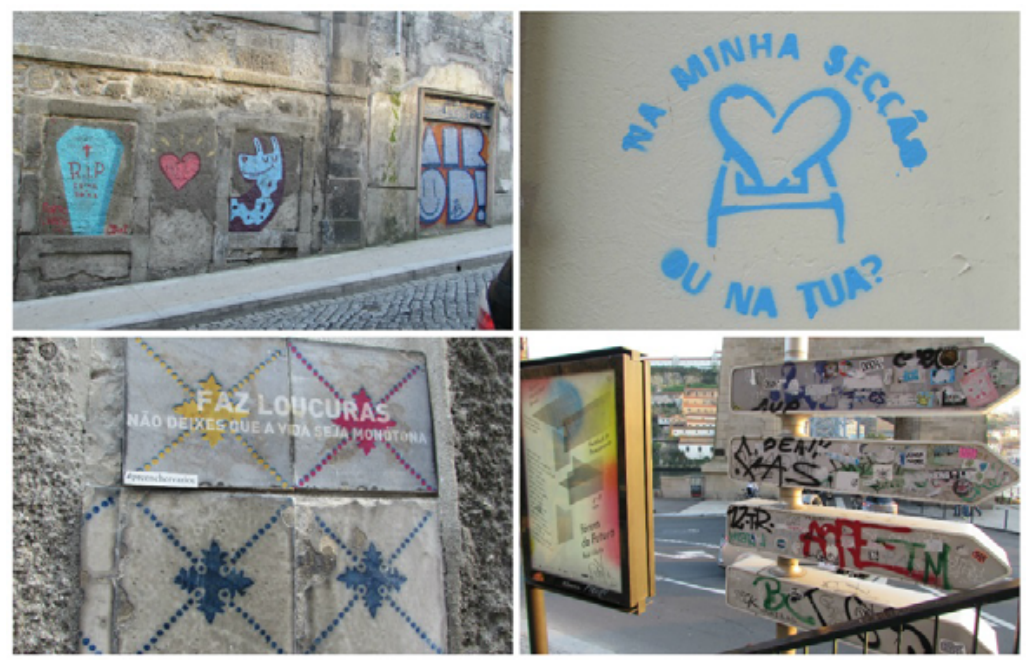

Figura 7. Currículo reclamado da cidade | @ Joana Lúcio (2015). 
Nestas quatro imagens (figua 7) temos evidência de uma apropriação aparentemente menos ordenada, aquilo que poderíamos designar (e frequentemente se designa) de vandalismo, mas que, numa análise mais apurada, vemos revestir-se de lógica e intencionalidade, mesmo que estas sejam, de alguma forma, anti-norma. No sentido dos ponteiros do relógio: graffiti que se restringe às zonas emparedadas de um edifício devoluto; um stencil que apela ao voto como forma de participação; uma intervenção sobre uma fachada de azulejaria tradicional, danificada, com a hashtag «preenchervazios»; o currículo formal (placas de sinalização) como plataforma para a expressão, para a transgressão, para o anti-formal.

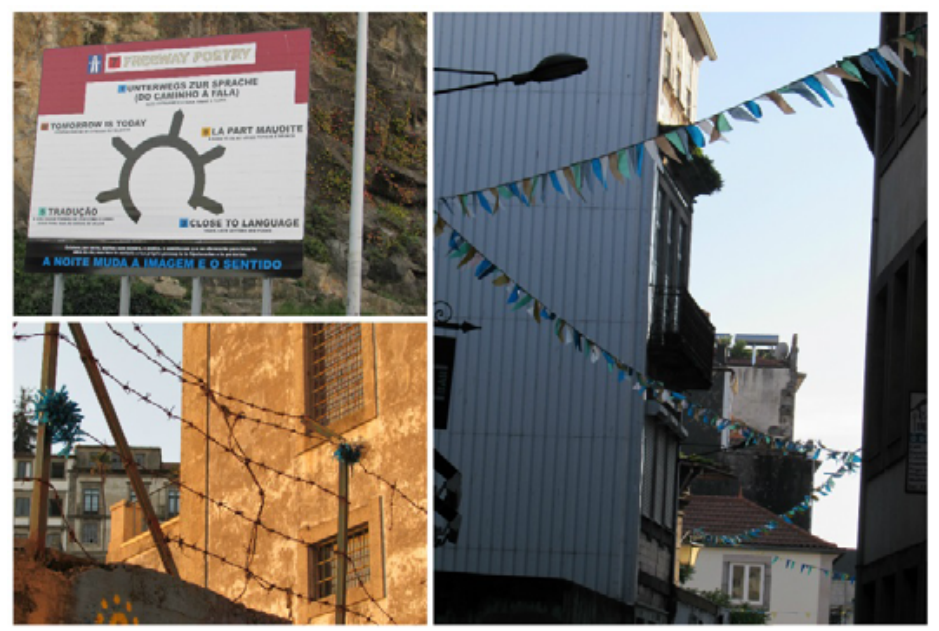

Figura 8. Currículo reclamado da cidade | @ Joana Lúcio (2015).

O esquecimento também faz parte do currículo educativo da cidade (figura 8). Os espaços outrora vivos e agora negligenciados testemunham as temporalidades da cidade: os vazios, as pausas, os ciclos. Na primeira imagem, em cima à esquerda, um outdoor que mimetiza uma sinalização de trânsito, referente a eventos culturais de há vários meses. Nas outras duas imagens, as decorações que sobrevivem largamente às festas da cidade. 


\section{A cidade como discurso, a cidade como projeto: metodologia e análise}

As imagens anteriores dão conta de um currículo educativo da cidade, que mais não é do que um compósito de discursos, de apropriações e de projetos sobre a cidade enquanto espaço de desenvolvimento social, educativo, cultural, etc., para atores individuais e coletivos. Os discursos dos interlocutores com quem contactámos no âmbito do projeto «Massarelos, Freguesia Educadora» dão conta de uma cidade multidimensional, passível de quase tantas apreensões distintas quantos são aqueles/as que a ocupam.

O projeto «Massarelos, Freguesia Educadora» (2006-2011), iniciativa de investigação e de intervenção, tinha um objetivo duplo: explorar a mediação enquanto trabalho social e educativo de especial relevo no contexto urbano e, simultaneamente, explorar o projeto de Cidade Educadora como plataforma mediadora do desenvolvimento socioeducativo da comunidade. Desenvolveu-se em duas fases (Abril/2006 - Junho/2007 e Dezembro/2007 - Julho/2011) e teve como pressuposto fundamental a ideia de que a socialização e a educação são, como já se aludiu, processos eminentemente transinstitucionais, que beneficiam de um sistema formativo integrado, que por sua vez se concretiza num projeto educativo local (Villar, 2007). O projeto teve uma dimensão dupla de investigação e intervenção e, nesse sentido, houve articulação com uma série de atores de relevo no contexto da freguesia (autarquia, rede educativa, movimento associativo e tecido empresarial), que forneceram dados importantes (através de entrevistas, questionários e grupos de discussão focalizada ou GDF) quanto ao seu papel socioeducativo e participaram em iniciativas de debate e promoção de um projeto de desenvolvimento integrado para o território.

Para as crianças e os jovens $(n=88)$, em particular, a cidade enquanto contexto de aprendizagem foi especialmente evidente. Falam simultaneamente sobre a aprendizagem como experiência omnipresente ao longo e ao largo da sua vida e do seu usufruto da cidade, e da impossibilidade de aprender em determinados espaços-tempos. Para além disso, identificam a ocorrência de diferentes tipos de aprendizagem em diferentes contextos (Lúcio, 2015, 2016). Realizaram-se seis GDF em que participaram crianças e jovens que viviam e/ou estudavam em Massarelos: 
Tabla 1. Listagem e caracterização dos grupos de discussão focalizada com crianças e jovens.

\begin{tabular}{|c|c|c|}
\hline Nível de escolaridade & Idades & $\begin{array}{c}\text { Número de } \\
\text { participantes }\end{array}$ \\
\hline Jardim de Infância & $5-6$ anos & 12 \\
\hline $1 .^{\circ}$ e $2 .^{\circ}$ ano & $6-8$ anos & 8 \\
\hline $3 .^{\circ}$ e $4 .^{\circ}$ ano & $8-10$ anos & 11 \\
\hline $6 .^{\circ}$ ano (grupo A) & $11-12$ anos & 20 \\
\hline $6 .^{\circ}$ ano (grupo B) & $11-12$ anos & 18 \\
\hline $9 . .^{\circ}$ ano & $14-17$ anos & 19 \\
\hline
\end{tabular}

À exceção dos três últimos GDF, em que participaram a totalidade dos grupos-turma, todos os outros foram objeto de seleção de participantes, processo esse que ficou a cargo dos/as docentes com quem o desenvolvimento das atividades de recolha de dados havia sido negociado. Construiu-se um guião orientador para estes GDF, que incluía questões como:

- O que é uma cidade? O Porto é uma cidade? Por quê?

- Quem decide o que se pode ou não pode fazer na cidade? Como se sabe se o que queremos fazer é possível ou não?

- Na nossa cidade, pode-se brincar na rua? Por quê? E noutras cidades? Por quê? Quem decide? Como? É importante brincar na rua? Por quê?

- Na nossa cidade, onde (em que sítios) podemos aprender? E para além da Escola e da família, há outros sítios onde podemos aprender? Que tipo de coisas aprendemos nesses sítios?

- Que direitos temos em relação à nossa cidade? E que deveres? Que direitos/deveres deviam existir?

- O que podíamos fazer para o Porto ser uma cidade melhor?

- O que é que as crianças/jovens como vocês podem fazer para tornar a nossa cidade um sítio melhor? Os/as adultos/as costumam dar atenção à opinião das crianças e jovens sobre estas questões? 
Enquanto indivíduos e enquanto parte de grupos, as crianças e os jovens têm direitos e deveres específicos em relação à cidade, e formas próprias de a percecionar e dela se apropriar enquanto espaço e enquanto ideia, ou seja, enquanto plataforma para o seu futuro e para o futuro da comunidade a que pertencem. Nesse sentido, «the acknowledgement of children's right to participate is indelibly connected, not only to an acknowledgement of their ability and willingness to do so, but also to their recognition as actors in their own right» (Lúcio \& I'Anson, 2015, p. 131). Reconhecer as crianças como cidadãos significa a aceitação da sua participação de acordo com os formatos mais ou menos estandardizados, mas também «recognizing their innovations, their creativity and even their negation - or subversion - of traditional models of participation and citizenship. The legitimacy of their status necessarily means a change in the scope of the concept of citizen participation» (Lúcio \& I'Anson, 2015, p. 131).

Os elementos visuais podem ser especialmente úteis no trabalho sobre os significados que a cidade tem para os mais jovens: a fotografia, os sistemas de informação geográfica e os desenhos, enquanto mapas mentais que permitem a identificação de recursos, redes, focos de interesse ou outros polos agregadores da vida local, lógicas e estratégias de mobilidade, mas também os vazios, as invisibilidades, o que se evita, se ignora ou se anula, e por quê. O conceito de linguistic turn (vd. Rorty, 1992) pode ser útil para a discussão da questão da análise de elementos visuais, na medida em que, enquanto movimento, se baseia na ideia de que a linguagem constitui a realidade, ou seja, de que aquilo que entendemos como o «real» não é se não uma convenção de nomenclaturas (designações) e caracterizações, convenção esta chamada linguagem. A ideia é que, mesmo quando se trata de contextos de investigação inovadores, de posturas investigativas desafiantes ou de procedimentos de recolha e análise de dados altamente complexos e multirreferenciais, a produção de conhecimento científico resvala inevitavelmente na necessidade de nomear, de designar, de transpor ideias, observações ou impressões em texto; texto esse sujeito a regras e limitações inerentes à utilização de determinado código linguístico. Concretizando: os desenhos que aqui apresentamos e procuramos analisar foram produzidos por crianças a frequentar o pré-escolar ou o primeiro ciclo do ensino básico, em contexto de escola (embora não em contexto de sala de aula), tendo-lhes simplesmente sido dada a indicação 
de que desenhassem «sobre a cidade». Estas condições de partida podem permitir-nos inferir que, não obstante a qualidade artística e criativa destes produtos, estes desenhos estão sujeitos a regras (de utilização da cor, de circunscrição no tempo e no espaço, de referência a aspetos visuais e relacionais concretos na vida destas crianças) que permitem a sua análise e a sua classificação enquanto textos.

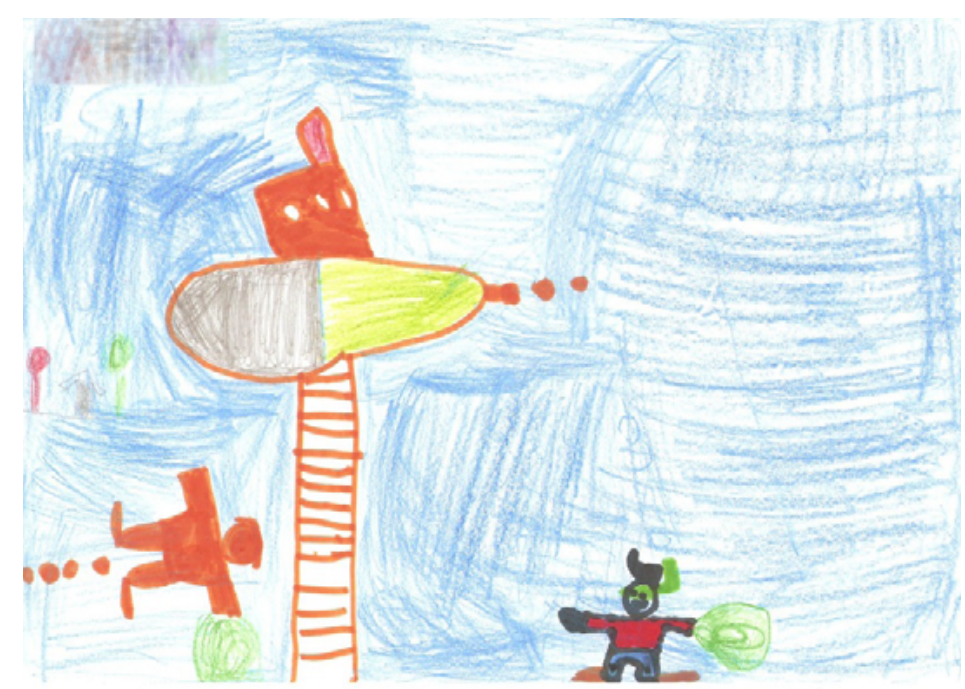

Figura 9. Desenho produzido por um dos rapazes que participou no GDF que teve lugar no jardim de infância.

Aquando das visitas ao jardim de infầncia e à escola EB1 que aceitaram colaborar na recolha de dados, com vista ao desenvolvimento dos GDF com crianças, solicitou-se, no final da atividade, aos participantes que, caso assim desejassem, fizessem cada um/a um desenho «sobre a cidade». A iniciativa não foi previamente planeada, ou seja, não havia previsão de recolha de dados deste tipo, mas tal verificou-se porque a oportunidade se apresentou: os GDF em que participaram estas crianças mais jovens tiveram, regra geral, uma duração relativamente curta em relação ao tempo previsto para a atividade; por outro lado, e como é habitual em escolas destes níveis de ensino, as folhas brancas e o material de desenho estão facilmente disponíveis - por ocasião dos dois GDF desenvolvidos na escola EB1 existia, inclusive, um copo com lápis de cor no centro de mesa em que decorreu a atividade. Assim sendo, e num golpe de oportunidade, decidiu-se solicitar a produção destes 
desenhos, considerados enquanto dados suscetíveis de análise textual, com vista à construção de uma visão mais complexa e detalhada acerca da perceção dos vários atores sociais sobre as potencialidades educativas do contexto que habitam.

Importa ainda salientar que o recurso aos métodos visuais, como os desenhos, tem a potencialidade de estimular a participação dos sujeitos junto dos quais se pretende recolher dados de investigação. Conforme sistematizam Niemi, Kumpulainen e Lipponen (2015), «[t]he use of visual methods [...] encourages the involvement of those who find reading and writing uninviting [...] In particular, visual and spatial activities - drawing diagrams and pictures, sorting images and creating new arrangements - have been seen as a way to provide interaction between research participants, supporting the establishment of connections and the building of understanding» (Niemi, Kumpulainen \& Lipponen, 2015, p. 139).

Entre os desenhos produzidos pelas crianças que frequentavam o jardim de infância, encontramos, com especial expressão, as preocupações relativas à preservação do ambiente e à gestão sustentável dos resíduos. A imagem anterior (figura 9) dá-nos conta de um cenário subaquático, onde é visível um submarino, uma escada e dois indivíduos com equipamento de mergulho, que seguram nas mãos sacos verdes (recolha de lixo) que aparentam estar cheios.
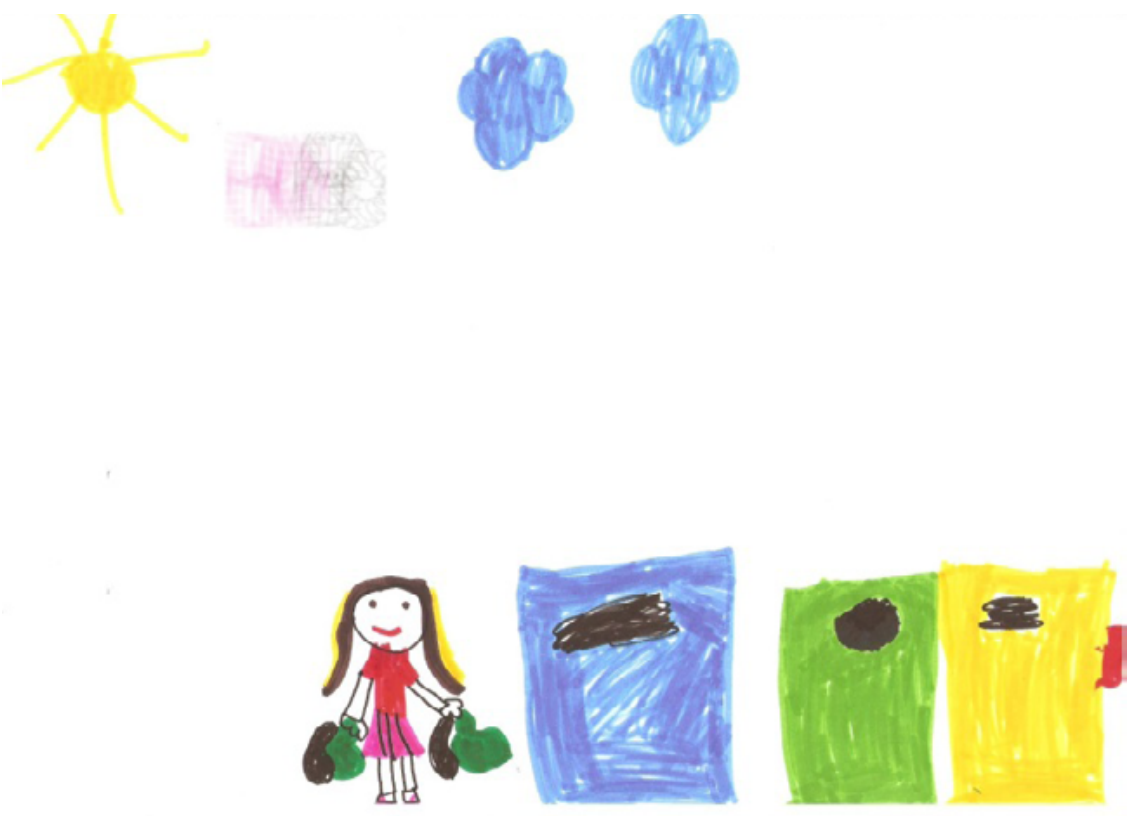

Figura 10. Desenho produzido por uma das raparigas que participou no GDF que teve lugar no jardim de infância. 
Os ecopontos, contentores para recolha de resíduos diferenciados, como o que observamos na imagem anterior (figura 10), são elementos explicitamente presentes em vários dos desenhos produzidos (55\%). Torna-se, assim, evidente, a preocupação das crianças com esta problemática e o seu potencial enquanto parceiros especialmente sensíveis e pró-ativos relativamente às questões ambientais.

O veículo automóvel e as estradas são outros elementos omnipresentes (57\%) nestes mapas mentais sobre a cidade, conforme é visível na imagem seguinte (figura 11).

Figura 11. Desenho produzido por uma das raparigas que participou no GDF que teve lugar na Escola EB1

Nesta imagem (figura 11) é ainda possível observar um edifício (de habitação ou de trabalho), representado explicitamente em $71 \%$ dos desenhos recolhidos. Percebe-se que o impacto do trânsito automóvel é sentido de forma particularmente forte por estas crianças, pelo que a sua participação em iniciativas de sensibilização junto das famílias e das organizações de relevo ao nível local seria também importante. 


\section{Considerações finais}

Como já tivemos oportunidade de discutir noutro âmbito (Lúcio, 2015), a apreciação que as crianças fazem da realidade urbana é muito semelhante à dos adultos: ambos os grupos reconhecem que a cidade é perigosa, que existem demasiados automóveis e que estes não respeitam os peões, que as infraestruturas estão sujas e/ou em mau estado de conservação, etc. No entanto, e como Tonucci (2004) tornou por demais evidente, as conclusões a que estes grupos chegam, e as suas disposições para agir a respeito, são bastante distintas: se os adultos dizem às crianças «visto que são estas as condições que prevalecem na cidade, deves ficar em casa, e se tiveres que sair, eu tenho de te acompanhar», as crianças dizem «visto que são estas as condições que prevalecem na cidade, temos que as mudar».

Conforme explicita Tonucci (2004), «uma cidade onde as crianças andam na rua é uma cidade segura, não só para elas mas também para os idosos, para as pessoas com deficiência e para todos os outros cidadãos» (Tonucci, 2004, p. 68). As crianças são, assim, um indicador ambiental sensível, e quando estas estão presentes, isso significa que a cidade encontrou a sua função «natural», enquanto espaço de partilha, cooperação e solidariedade. Se, quando falamos de planeamento urbano, nem sempre é possível começar do zero, pelo menos é quase sempre possível reimaginar, reinventar, reabilitar. $\mathrm{O}$ faz-de-conta é um exercício que às crianças surge com bastante naturalidade: enquanto que, para os adultos, pode ser difícil olhar para o edificado noutra perspetiva que não a de algo acabado, para os mais jovens o mundo é pluripotencial.

É da responsabilidade dos municípios, como o é das escolas, das associações, das empresas, dos decisores e de todos nós olhar para a cidade e vê-la como constructo fundamental do nosso passado, do nosso presente e do nosso futuro. Os recursos visuais, como as fotografias, os desenhos e outros media, podem ser particularmente úteis neste intento.

Estes desenhos constituem mapas mentais na medida em que se tratam de representações das perceções dos seus autores relativamente às suas áreas de interação. Conforme explicita Lynch (2009), «a criação da imagem ambiental é um processo duplo entre observador e observado. Aquilo que se vê é baseado 
na forma exterior, mas a forma como isso se interpreta e organiza e como se dirige a atenção afeta, por sua vez, o que é visto» (Lynch, 2009, pp. 133-134). São, simultaneamente, instrumentos e produtos de um processo de produção de conhecimento cujo referente é o local. Enquanto mapas, cartografam essencialmente problemas e recursos: a poluição e os sistemas de gestão de resíduos urbanos; a «colonização» automóvel e os espaços disponibilizados especificamente para usufruto das crianças (parques infantis). De fora, ficam as redes, a sociabilidade, a interação, a comunidade: embora as figuras humanas apareçam em $69 \%$ dos desenhos produzidos, em apenas $27 \%$ desses surge mais do que uma figura humana - e, portanto, a sugestão de interação. Na maioria dos desenhos em que surge mais do que uma figura humana, estamos perante representações de indivíduos a conduzir (uma pessoa por veículo).

Embora esta iniciativa de investigação não tivesse a pretensão de constituir-se como cartografia social (vd. Villasante, Montañés \& Martí, 2000; Lardoyet \& González, 2011), não é displicente pensar os desenhos das crianças enquanto mapas mentais e, nesse sentido, enquanto ferramentas de participação: de expressão de uma voz simultaneamente individual e coletiva, simultaneamente assente no passado e projetada no futuro. Se retratam e relatam a cidade presente e amiúde «denunciam» as suas limitações, estes desenhos constituem idealizações da cidade.

Assumindo o projeto da Cidade Educadora a importância de uma participação alargada, estes e outros recursos visuais serão certamente úteis na promoção e consolidação do papel das crianças e dos jovens enquanto cidadãos e co-construtores deste projeto.

\section{Referências bibliográficas}

Ascher, F. (2010). Novos Princípios do Urbanismo, seguido de Novos Compromissos Urbanos. Um léxico. Lisboa: Livros Horizonte.

Benevolo, L. (2006). A Cidade e o Arquitecto. Lisboa: Edições 70.

Bernet, J. T. (1990). «Introducción». In AAVV, La ciudad educadora/La ville éducatrice. Barcelona: Ajuntament de Barcelona, 13-21.

BorJa, J. \& Muxí, Z. (2003). El Espacio Público: Ciudad y ciudadanía. Barcelona: Diputació de Barcelona - Xarxa de Municipis/Electa. 
Gómez-Granell, C. \& Vila, I. (2003). A Cidade como Projeto Educativo. Porto Alegre: Artmed.

Lardoyet, S. H., \& González, G. G. (2011). La Investigación Acción Participativa en el Voluntariado. El voluntariado como motor del cambio social. Acontece, vivencias, haceres y saberes, 16(2), 1-8.

LúCIO, J. (2015). «Talking about the city: Focus group discussions about the city and the community as developmental grounds with children aged 5-17», European Educational Research Journal, 14(2), 167-176.

- (2016). «Young People's Appropriations of Life and Education in the City». In Angela Million, Anna Juliane Heinrich \& Thomas Coelen (eds.), Education, Space and Urban Planning: Education as a Component of the City. Switzerland: Springer International Publishing, 159-166.

— \& I'Anson, J. (2015). «Children as members of a community: Citizenship, participation and educational development - an introduction to the special issue», European Educational Research Journal, 14(2), 129137.

LyNCH, K. (2007). A Boa Forma da Cidade. Lisboa: Edições 70.

— (2009). A Imagem da Cidade. Lisboa: Edições 70.

Marina, J. A., Rodríguez, J. \& Vintró, E. (2007). «Repensar les Ciutats des de l'Educació». In À. D.-D. Barcelona, Ciutat.edu: Nous reptes, nous compromisos. Barcelona: Diputació de Barcelona - Xarxa de Municipis, 78-82.

Merino, A. \& Plana, J. (2007). La Ciudad Educa: Aportaciones para una política educativa local. Barcelona: Ediciones del Serbal.

Niemi, R., Kumpulainen, K. \& Lipponen, L. (2015). Pupils as active participants: Diamond ranking as a tool to investigate pupils' experiences of classroom practices. European Journal of Educational Research, 14(2), 138-150.

PAmiès, J. (2007). «Educación, Ciudad y Economía». In Á. Merino, \& J. Plana, La Ciudad Educa (pp. 337-350). Barcelona: Ediciones del Serbal.

Rorty, R. M. (1992). The Linguistic Turn: Essays in philosophical method. Chicago: The University of Chicago Press.

Tonucci, F. (2004). La Ciudad de los Niños. Un modo nuevo de pensar la ciudad. Madrid: Fundación Germán Sánchez Ruipérez.

Villar, M. B. (2007). A Cidade Educadora. Nova perspectiva de organização e intervenção municipal. Lisboa: Instituto Piaget.

Villasante, T. R., Montañés, M., \& Martí, J. (2000). La Investigación Social Participativa. Mataró: El Viejo Topo. 
